\title{
Maintenance of hPSCs under Xeno-Free and Chemically Defined Culture Conditions
}

\author{
Jung Jin Lim ${ }^{1, *}$, Hyung Joon Kim³,*, Byung-ho Rhie ${ }^{1}$, Man Ryul Lee ${ }^{2}$, \\ Myeong Jun Choi ${ }^{3}$, Seok-Ho Hong ${ }^{4}$, Kye-Seong Kim ${ }^{1,5}$ \\ ${ }^{I}$ Department of Biomedical Science, Graduate School of Biomedical Science and Engineering, Hanyang University, Seoul, Korea \\ ${ }^{2}$ Soonchunhyang Institute of Medi-bioscience, Soonchunhyang University, Cheonan, Korea \\ ${ }^{3}$ 1st Research Center, Axceso Biopharma Co., Ltd., Yongin, Korea \\ ${ }^{4}$ Department of Internal Medicine, School of Medicine, Kangwon National University, Chuncheon, Korea \\ ${ }^{5}$ College of Medicine, Hanyang University, Seoul, Korea
}

Previously, the majority of human embryonic stem cells and human induced pluripotent stem cells have been derived on feeder layers and chemically undefined medium. Those media components related to feeder cells, or animal products, often greatly affect the consistency of the cell culture. There are clear advantages of a defined, xeno-free, and feeder-free culture system for human pluripotent stem cells (hPSCs) cultures, since consistency in the formulations prevents lot-to-lot variability. Eliminating all non-human components reduces health risks for downstream applications, and those environments reduce potential immunological reactions from stem cells. Therefore, development of feeder-free hPSCs culture systems has been an important focus of hPSCs research. Recently, researchers have established a variety of culture systems in a defined combination, xeno-free matrix and medium that supports the growth and differentiation of hPSCs. Here we described detailed hPSCs culture methods under feeder-free and chemically defined conditions using vitronetin and TeSR-E8 medium including supplement bioactive lysophospholipid for promoting hPSCs proliferation and maintaining stemness.

Keywords: Embryonic stem cells, Induced pluripotent stem cells, Feeder-free, Chemically defined conditions, Extracellular matrices

Received: July 19, 2019, Revised: September 3, 2019,

Accepted: September 16, 2019, Published online: October 31, 2019 Correspondence to Kye-Seong Kim

Department of Biomedical Science, Graduate School of Biomedical Science and Engineering, Hanyang University, 222 Wangsimni-ro, Seongdong-gu, Seoul 04763, Korea

Tel: +82-2-2220-0607, Fax: +82-2-2220-2422

E-mail: ks66kim@hanyang.ac.kr

Co-Correspondence to Seok-Ho Hong

Department of Internal Medicine, School of Medicine, Kangwon National University, 1 Kangwondaehak-gil, Chuncheon 24341, Korea Tel: +82-33-250-7819, Fax: +82-33-244-2367

E-mail: shhong@kangwon.ac.kr

${ }^{*}$ These authors contributed equally to this work.

(c) This is an open-access article distributed under the terms of the Creative Commons Attribution Non-Commercial License (http://creativecommons.org/ licenses/by-nc/4.0/), which permits unrestricted non-commercial use, distribution, and reproduction in any medium, provided the original work is properly cited.

Copyright (c) 2019 by the Korean Society for Stem Cell Research

\section{Introduction}

The first derivation in 1998 of human embryonic stem cell (hESC) line was achieved by culturing inner cell mass on mouse embryonic fibroblasts $(\mathrm{mEF})$ in the medium containing chemically undefined components such as fetal bovine serum (FBS) (1). Human induced pluripotent stem cells (hiPSCs) were also established in the same conditions as hESCs (2). These undefined culture conditions with animal-derived components hamper analysis of molecular mechanisms that control pluripotency, self-renewal and differentiation as well as the possible clinical application of human pluripotent stem cells (hPSCs) (3). Thus, the hPSC field gradually shifted to the development of chemically defined culture system 
by removal of feeder layers, serum and growth factors and replacement of Matrigel to human recombinant matrices (See Table 1) (1, 4-9). Despite these innovative advances, hPSC cultures still exhibit phenotypic and functional heterogeneity, and remain to be optimized for assurance of functionality and genetic stability over long-term maintenance $(10,11)$. Here, we describe the major improvements of hPSC culture system and chemically defined culture protocol for long-term maintenance. In addition, we briefly introduce the beneficial effect of bioactive lysophospholipid in maintaining hPSCs.

\section{From feeder to feeder-free system for hPSCs culture}

The first establishment of hESCs has described by using with inactivated mEFs as feeder cells and FBS-containing culture medium (1). Feeder-cells such as mEFs support the self-renewal of hESCs by the secretion of essential growth factors, cytokines and extracellular matrices (ECM) such as transforming growth factor $\beta$ (TGF $\beta$ ), activin A, laminin-511 and vitronectin (12). Those feeder-dependent systems support the stem cells by the mimetic microenvironment. Like other hESCs, hiPSCs depend on the support of feeder cells such as mEFs (Fig. 1A) or human fibroblast. There are certain drawbacks to the feeder-dependent culture systems, most notably the introduction of animal-derived cells to the human stem cell environment. Next, FBS (Fig. 1Aa) was replaced with knockout serum replacement (KSR) and basic fibroblast growth factor 2 (FGF2) (Fig. 1Ab). mEF was also changed with human feeder cells (13). Although the use of human feeder cells circumvented the use of animal-derived feeder cells, this culture system is fully dependent on the condition of human feeder cells and the function of the human feeder cells in the hPSCs co-culture system was still not fully understood.

The first major step in optimizing the hPSCs culture environment was to culture the stem cells independently from the feeder cells. To achieve reliable and safe production of hPSCs, it is desirable to use reagents that are defined, qualified, and preferably derived from a non-animal source. Furthermore, it should need an appropriate matrix to achieve the feeder free system. Therefore, development of feeder-free human PSCs culture systems has been an important focus of stem cell research. In 2006, researchers in WiCell reported that feeder-independent hESC culture that includes protein components solely derived from recombinant sources or purified from human material. They described the derivation of new hESC lines in these defined culture conditions. This first defined medium significantly improved hESC culture, and was commercially released as TeSR1, becoming the most widely-published feeder-free medium, used in over 1,100 peerreviewed publications. This media is composed of a DMEM/F12 base supplemented with human serum albumin, vitamins, antioxidants, trace minerals, specific lipids and cloned growth factors (7).

Table 1. Major improvements of hPSC culture protocols

\begin{tabular}{|c|c|c|c|}
\hline $\begin{array}{l}\text { hPSC } \\
\text { types }\end{array}$ & Culture condition & Point of improvement & Reference \\
\hline hESCs & $\begin{array}{l}\text { Feeder: Inactivated MEFs } \\
\text { Medium: DMEM } 12+10 \% \text { FBS }\end{array}$ & $\begin{array}{l}\text { First establishment of human pluripotent stem } \\
\text { cells }\end{array}$ & Thomson et al. 1998 (1) \\
\hline hESCs & $\begin{array}{l}\text { Coating: Laminin (vs Matrigel) } \\
\text { Medium: MEF-CM }\end{array}$ & $\begin{array}{l}\text { Feeder-free culture system } \\
\text { Replacement Matrigel to Laminin }\end{array}$ & Xu et al. 2001 (4) \\
\hline hESCs & $\begin{array}{l}\text { Feeder: Inactivated human fetal and adult } \\
\text { fibroblast } \\
\text { Medium: DMEM12+20\%FCS }\end{array}$ & Long-term propagation on human feeder cells & Richards et al. 2002 (5) \\
\hline hESCs & $\begin{array}{l}\text { Feeder: Inactivated human fetal and adult } \\
\text { fibroblast } \\
\text { Medium: KO-DMEM } 12+20 \% \mathrm{HS}\end{array}$ & $\begin{array}{l}\text { First establishment and propagation of hESC } \\
\text { line in xeno-free conditions }\end{array}$ & Richards et al. 2003 (6) \\
\hline hESCs & $\begin{array}{l}\text { Coating: Human matrix (Laminin, Vitronectin, } \\
\text { Collagen, Fibronectin) } \\
\text { Medium: TeSR1 }\end{array}$ & $\begin{array}{l}\text { Derivation and propagation in defined culture } \\
\text { condition }\end{array}$ & Ludwig et al. 2006 (7) \\
\hline $\begin{array}{l}\text { hESCs } \\
\text { hiPSCs }\end{array}$ & $\begin{array}{l}\text { Coating: Vitronectin } \\
\text { Medium: E8 }\end{array}$ & $\begin{array}{l}\text { Derivation and propagation in } \\
\text { chemically-defined condition }\end{array}$ & Chen et al. 2011 (8) \\
\hline $\begin{array}{l}\text { hESCs } \\
\text { hiPSCs }\end{array}$ & $\begin{array}{l}\text { Coating: Laminin, Vitronectin } \\
\text { Medium: E8+Kenpaullone }(0.75 \mu \mathrm{M})+ \\
\text { ID-8 }(0.5 \mu \mathrm{M})+\text { Tacrolimus }(5 \sim 200 \mathrm{pM})\end{array}$ & $\begin{array}{l}\text { Derivation and propagation in } \\
\text { chemically-defined and growth factor-free } \\
\text { condition }\end{array}$ & Yasuda et al. 2018 (9) \\
\hline
\end{tabular}

FCS: Fetal calf serum, HS: Human serum, KO: KNOCKOUT. 


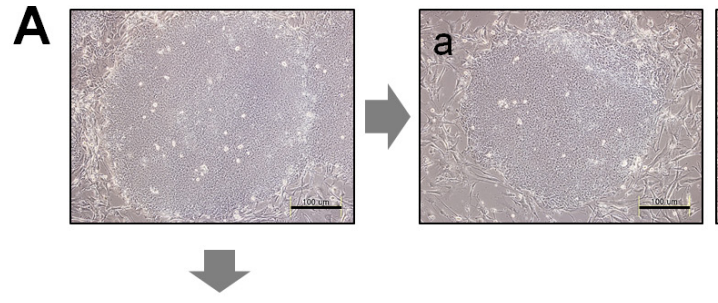

Passage 1

B
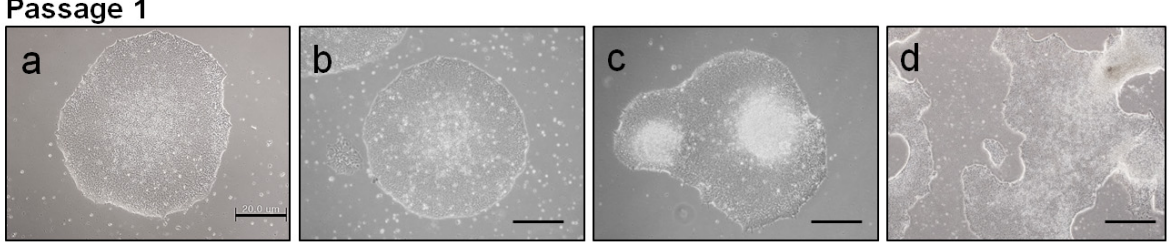

Passage 5

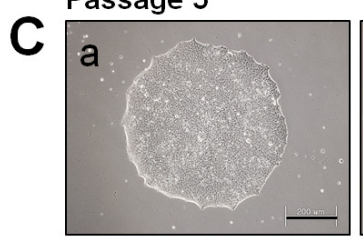

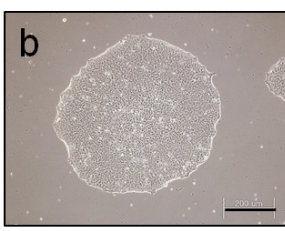
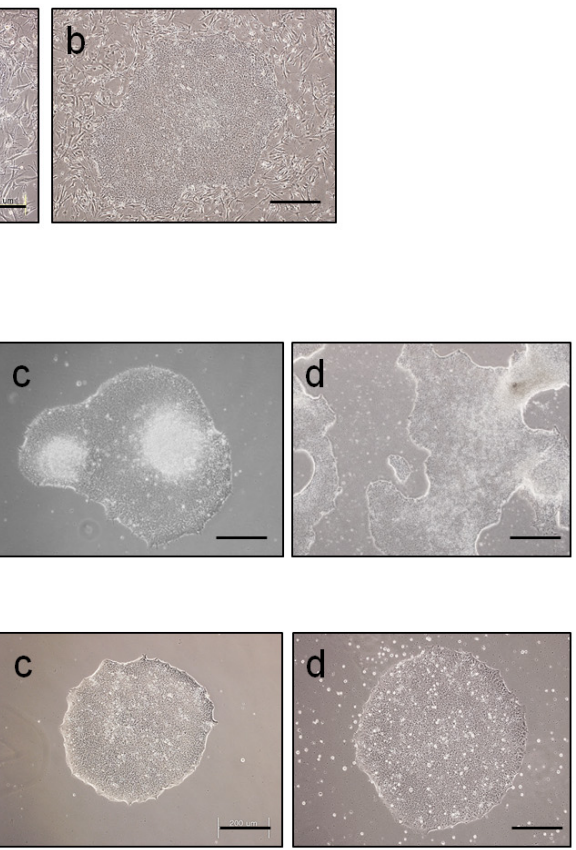

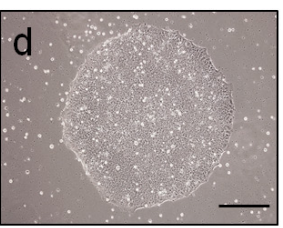

Fig. 1. Application of feeder-free system for hPSCs culture. (A) Phase contrast image of cultured hPSCs maintained in undefined medium on MEF feeder layer with $20 \%$ FBS (a) or $20 \%$ KSR (b). (B, C) Phase contrast image of cultured hPSCs maintained in chemical defined medium on different kinds of coating matrix (a: Matrigel, b: Vitronectin XF, c: rhLaminin-521 and d: iMatrix511) at passage 1 (B) and 5 (C). All matrix materials were used according to the manufacturer's instructions. Scale bar, A: $100 \mu \mathrm{m}$; B: $200 \mu \mathrm{m}$.
TeSR2 is a next version of mTeSR1 derived from TeSR1 media family which provides improved culture conditions for feeder-free maintenance of hPSCs while enabling a more defined and xeno-free culture environment for basic research, high-throughput gene profiling studies and preclinical applications. TeSR2 combines the advantages of a feeder-free culture system with the added value of being free of xenogenic components. Complete TeSR2 contains recombinant human basic FGF and recombinant human TGF- $\beta$. Addition of further growth factors is not required (14). More recently, Thomson and coworkers developed chemically defined TeSR-E8 medium (E8 medium), which is a derivative of mTeSR1 containing eight components, that lacks both serum albumin and $\beta$-mercaptoethanol. This E8 medium, combined with EDTA passaging, may be suitable for culturing a broad range of hPSC lines, particularly to improve episomal vector-based reprogramming efficiencies as well as experimental consistency (8). Currently available commercial hPSC culture media and their components are listed in Table 2.

\section{Matrices for feeder-free system}

The ECM is synthesized, secreted, and structured by embryonic cells from initial steps of developmental process. Composition, structure and function of ECM has been identified in detail recently and has revealed that the microenvironment including ECM is critically important for survival, cell growth, morphogenesis and differentiation (15). The extracellular matrix of many $(16,17)$, if not all, composed of certain unique macromolecules, including, laminin (18, 19), a heparan sulfate proteoglycan (20), type IV collagen (16) and entactin (21). Among those, Laminin is the first extracellular matrix protein expressed in two- to four-cell stage mouse embryos and is the main component of basement membranes of all basal laminae in mammals $(22,23)$. Interacting with integrin heterodimers such as $\alpha 1 \beta 1, \alpha 2 \beta 1, \alpha 3 \beta 1, \alpha 6 \beta 1$, and $\alpha 6 \beta 4$ on the cell surface, laminin induces signals for promoting cell adhesion, growth, and migration. Previous reports indicated that the laminin receptor was found to be highly expressed on ESCs and embryonal carcinoma cells (24, 25).

1. Matrigel, which is a commercially available protein mixture extracted from a whole mouse sarcoma tissue, has been one of the most widely used extracellular components for feeder-and serum-free culture of hPSCs (Fig. 1 $\mathrm{Ba}, 1 \mathrm{Ca})$. It contains mostly types I and IV collagens, laminin, entactin, heparan sulfate proteoglycan, matrix metalloproteinases, undefined growth factors, and chemical compounds (26-29). Although it is widely used for research applications, it is important to note that Matrigel, which is a semi-chemically defined, xenogeneic substrate, cannot be used for generation of clinical-grade hPSCs. Previous studies have shown that Matrigel contains various growth factors including TGF- $\beta$, epidermal growth factor (EGF), insulin-like growth factor 1, bFGF, and platelet-derived growth factor (PDGF). Despite its availability and ease of use, Matrigel is not ideal for potential 
Table 2. Commercial media for hPSC culture

\begin{tabular}{|c|c|c|c|c|}
\hline Medium & Formula & Extracellular matrix & $\mathrm{XF} / \mathrm{CD}$ & Brand \\
\hline $\mathrm{mTeSR}^{\mathrm{TM}} 1$ & $\begin{array}{l}\text { DMEMF12, BSA, bFGF, TGF } \beta \text {, Insulin, Transferrin, } \\
\text { Cholesterol, Lipids, Pipecolic acid, GABA, } \\
\beta \text {-mercaptoethanol }\end{array}$ & Matrigel ${ }^{\circledR}$, Vitronectin & NA & $\begin{array}{l}\text { STEMCELL } \\
\text { Technologies }\end{array}$ \\
\hline $\mathrm{TeSR}^{\mathrm{TM}} 2$ & $\begin{array}{l}\text { DMEM/F12, HSA, bFGF, TGF } \beta \text {, Insulin, Transferrin, } \\
\text { Cholesterol, Lipids, Pipecolic acid, GABA, } \\
\beta \text {-mercaptoethanol }\end{array}$ & Matrigel $^{\mathbb{R}}$, Vitronectin & $\begin{array}{l}\mathrm{XF} \\
\mathrm{CD}\end{array}$ & $\begin{array}{l}\text { STEMCELL } \\
\text { Technologies }\end{array}$ \\
\hline Essential $8^{\mathrm{TM}}$ & $\begin{array}{l}\text { DMEMF12 bFGF, TGF } \beta \text {, Insulin, Transferrin, } \\
\text { Selenium, Ascorbic acid }\end{array}$ & Matrigel $^{\mathbb{R}}$, Vitronectin & $\begin{array}{l}\mathrm{XF} \\
\mathrm{CD}\end{array}$ & $\begin{array}{l}\text { Thermo Fisher } \\
\text { Scientific }\end{array}$ \\
\hline $\mathrm{TeSR}^{\mathrm{TM}}-\mathrm{E} 8^{\mathrm{TM}}$ & $\begin{array}{l}\text { DMEMF12, bFGF, TGF } \beta \text {, Insulin, Transferrin, } \\
\text { Selenium, Ascorbic acid }\end{array}$ & Matrigel $^{\circledR}$, Vitronectin & $\begin{array}{l}\mathrm{XF} \\
\mathrm{CD}\end{array}$ & $\begin{array}{l}\text { STEMCELL } \\
\text { Technologies }\end{array}$ \\
\hline StemPro $^{(\mathbb{R}}$ & $\begin{array}{l}\text { DMEMF12, BSA, bFGF, TGF } \beta \text {, Activin, Transferrin, } \\
\text { LR3-IGF1, HRG1 } \beta\end{array}$ & Geltrex $^{(\mathbb{R}}$ & NA & $\begin{array}{l}\text { Thermo Fisher } \\
\text { Scientific }\end{array}$ \\
\hline PluriSTEM $^{\mathrm{TM}}$ & $\begin{array}{l}\text { DMEMF12, HAS, Activin A, TGF } \beta 1 \text {, bFGF, Lipids, } \\
\text { Insulin, Transferrin, Selenium }\end{array}$ & Not defined & $\mathrm{XF}$ & Millipore \\
\hline $\begin{array}{l}\text { StemMACS } \\
\text { iPS-Brew XF }\end{array}$ & $\begin{array}{l}\text { DMEMF12, NaHCO3, L-Ascorbic Acid, Selenium, } \\
\text { Transferrin, Insulin, bFGF }\end{array}$ & $\begin{array}{l}\text { Matrigel }^{\circledR} \text {, Geltrex } \\
{ }^{\circledR}, \text { Laminin-511, } \\
\text { Lamin-521, iMatrix-511, Vitronectin }\end{array}$ & $\mathrm{XF}$ & $\begin{array}{l}\text { Miltenyi } \\
\text { Biotec }\end{array}$ \\
\hline StemFit $^{R}$ & DMEMF12, NaHCO3, L-Ascorbic Acid, Selenium, & ${\text { iMatrix-511, } \text { Matrigel }^{\mathbb{R}} \text {, Geltrex }}^{(\mathbb{R}}$, & $\mathrm{XF}$ & Ajinomoto \\
\hline Basic02/03 & $\begin{array}{l}\text { Transferrin, Insulin, bFGF, } 21 \text { Amino acids, five } \\
\text { trace minerals and growth factors (including bFGF) }\end{array}$ & Laminin-521 & $\mathrm{CD}$ & Company \\
\hline StemFlex ${ }^{\mathrm{TM}}$ & Undisclosed & $\begin{array}{l}\text { Geltrex }^{\mathrm{TM}} \text { (for clump cell), } \\
\text { rhLaminin-521 (for single cell) }\end{array}$ & NA & $\begin{array}{l}\text { Thermo Fisher } \\
\text { Scientific }\end{array}$ \\
\hline $\begin{array}{l}\text { Cellartis }^{\circledR} \\
\text { DEF-CS }\end{array}$ & Undisclosed & $\begin{array}{l}\text { TaKara Clontech iMatrix-511, } \\
\text { Corning Synthemax }\end{array}$ & $\begin{array}{l}\mathrm{XF} \\
\mathrm{CD}\end{array}$ & Takara \\
\hline
\end{tabular}

NA: not available (neither XF nor CD), XF: xeno-free, CD: chemically defined medium.

clinical application of hPSCs because it is animal-derived and xenogenic pathogens can be transmitted through culture even though no feeder cells are present. In addition, it also varies extensively from batch to batch.

2. Vitronectin is an adhesive glycoprotein $(75 \mathrm{kDa})$ of the hemopexin family which is abundantly found in humans such as serum, ECM, and bones $(30,31)$. It is composed of 459 amino acid residues of human VTN gene and classed in three domains; which are B domain (N-terminal) and two hemopexin homology domains (central and C-terminal) (32). Vitronectin recognizes the cells expressing its receptors: integrins $\alpha \mathrm{v} \beta 1, \alpha \mathrm{v} \beta 3, \alpha \mathrm{v} \beta 5$ or $\alpha \operatorname{IIb} \beta 3$ (33). rhVitronectin (recombinant human vitronectin) is a recombinant, full or partial length human single-chain and monomeric protein. Recently, several studies of functionality of integrins on hESCs have revealed that integrin families are important for the attachment of hESCs in in vitro condition (34). Vitronectin also contains an $\operatorname{RGD}(5,6,9)$ sequence, which is a binding site for membrane-bound integrins, e.g., vitronectin receptor, which serves to anchor cells to the ECM. In addition, vitronectin binds to the integrin $\alpha \mathrm{v} \beta 5$. Especially, the integrin $\alpha \mathrm{v} \beta 5$ of vitronectin receptor can facilitate cells not only in binding to the matrix, but also in maintaining human self-renewal and pluripotency, even when the cells are blocked from binding to integrin $\beta 1$ (35). rhVitronectin was a defined functional alternative to Matrigel or laminin for supporting sustained self-renewal and pluripotency of hiPSC. When used with Essential 8 medium, rhVitronectin has demonstrated the ability to maintain pluripotency and the normal growth characteristics in multiple human PSCs (Fig. 1Bb, 1Cb). rhVitronectin also has shown to support hiPSCs growth for a long-term cultivation without any karyotypic abnormalities and to maintain the pluripotency (36).

3. Laminin, which is a major component of the ECM of all basal laminae in vertebrates, can support the pluripotency of hPSCs. The combination of a human laminin coating with defined medium supplements, such as recombinant bFGF and the additional growth factors SCF, and LIF, was shown to support the growth and maintenance of undifferentiated hESCs (37). Laminin (LN)-511 and -521 are a key cell adhesion protein and widely expressed in the body, such as cells from muscle, vascular, nervous, and inner cell mass of the embryo $(38,39)$. It has been reported that hiPSCs self-renew on the recombinant LN-511 fragment. This fragment contains the C-terminal end of LN-511 that contains an integrin-binding site. Plating of human iPSCs at the same densities on 
LN-521 has revealed that more cells survive on LN-521, suggesting that other parts of these large multi-domain laminin molecules interact with, and influence, the cells (40). Both LNs also have strong interaction with the integrin $\alpha 6 \beta 1$, which regulate focal adhesion kinase (FAK) signaling in hPSCs, and disruption of this pathway results in hPSC differentiation (41). We have confirmed that hiPSCs can be maintained in an undifferentiated state on recombinant LN-521-coated plates after dissociation and passaging (Fig. 1Bc, 1Cc). However, LN-521 can be used in fully animal-component-free and efficient culture systems for hiPSCs, LN-521 still remains with a high price and possible batch-to-batch variation.

\section{Test of chemically defined system for hPSCs culture}

Without feeder cells, the culture is entirely dependent on the quality of the medium for maintenance and proliferation of healthy stem cells. The first chemically defined medium formulation TeSRl (7) substantially improved the culture of human PSCs, and was commercially released as mTeSR1 (Fig. 2 upper a, lower a). The combination of mTeSRl medium and Matrigel substrate creates a rich environment to support hPSCs. However, mTeSR1 medium contains animal-derived components and relies on substantial amounts of bFGF to maintain undifferentiated hPSCs (Table 1). Recently, a more streamlined medium for feeder-free cell culture was developed, called NutriStem (Corning, USA), iPS-Brew XF (Miltenyi Biotec, USA), StemFit hPSC Medium (AJINOMOTO, Japan). Those hPSCs medium are more defined, xeno-free, and contains very low levels of growth factors and other proteins and/or HSA, including bFGF (Fig. 2 upper cd, lower cd, Table 1). The low protein composition avoids potential bias, inhibition, or other effects on subsequent differentiation of the cells. TeSR-E8 medium which developed by Chen et al. (8) is a complete defined, feeder-free medium compare to mTeSR1 or NutriStem formulation for the growth and expansion of human PSCs. TeSR-E8 me- dium contains only the eight components most needed to maintain pluripotent stem cells. Cultures are grown complete with their vitronectin (VTN-N) substrate, which together with TeSR-E8 medium make an effective feeder-free culture system for pluripotent stem cells (Fig. 2 upper b, lower b, Table 1). As mentioned above, rhVitronectin (VTN-N) has been shown to support human PSCs attachment and survival better than wild-type vitronectin. Combination of recombinant biomaterials and complete chemically defined medium may offer a fully defined culture system with a lower cost and higher consistency. In this study, we described detailed protocols to support the culture of hPSCs using TeSR-E8 medium on rhVitronectin-coated culture plate with small addition of bioactive lysophospholipid.

\section{Supplement of bioactive lysophospholipid for improving proliferation of hPSCs}

A lipid mediator sphingosine-1-phospahate (S1P) is known to exert multiple responses, such as proliferation, survival and cytoskeletal rearrangement, via its $G$ protein-coupled receptor (GPCR) in many cell types $(42,43)$. Enhancement of PSCs growth rate under fully defined conditions is an important goal to facilitate the robust proliferation of cells to a clinical standard and to enable controlled differentiation of human PSCs (44). Previous studies have implicated S1P as a valuable component of defined culture medium to maintain PSCs. Supplementing S1P in the defined culture system led to a dose-dependent reduction in the level of apoptosis in PSCs while increasing their proliferation rate (45). Phytosphingosine-1-phosphate (P1P) is derived from plants, and is structurally similar to S1P, an endogenous signal lipid in mammalian cells $(46,47)$. Here we show that an enhanced synthetic sphingolipid, O-cyclic phytosphingosine-1-phosphate (cP1P), has a potential role in increment of proliferation and decrease of apoptosis and/or modulate self-renewal potential of the hPSCs. cP1P treatment appears to improve pro-



Fig. 2. hPSCs culture on vitronectin in chemically defined media. Phase contrast image of cultured hPSC maintained on Vitronectin XF in different kinds of chemically defined medium (a: mTeSR1, b: TeSR-E8, c: iPS-Brew $\mathrm{XF}$ and d: StemFit) at subculture passages 2 (upper) and 4 (lower). All culture media were used according to the manufacturer's instructions. All scale bar, $200 \mu \mathrm{m}$. 
liferation of PSC by the expansion of total cell populations associated with cell cycle progression (Fig. $3 \mathrm{~A} \sim \mathrm{D})$. cP1P also enhances protein expression of pluripotency markers (OCT4, REX-1, and KLF4) (Fig. 3E).

\section{Materials and Methods}

\section{Cell lines}

- hESCs (H9, WiCell Research Institute, USA; CHAhES 15, CHA Stem Cell Institute, Korea).

- Note: These cell lines were initially derived and expanded on $\mathrm{mEF}$ cells and later adapted to culture on vitronectin.

- hiPSCs (CMC-hiPSC-003, Catholic Medical Center, Korea; Registered in National Stem Cell Bank at Korea National Institute of Health).

- Note: This cell line was generated by non-integrating Sendai virus encoding OCT4, KLF4, SOX2 and c-MYC and propagated on vitronectin.

\section{Reagents}

- ROCK Inhibitor Y-27632 (Tocris, $10 \mathrm{mg}$, cat. no. 1254, UK)

- Vitronectin $\mathrm{XF}^{\mathrm{TM}}$ (STEMCELL Technologies, $2 \mathrm{ml}$, cat. no. 07180, Canada)

- CellAdhere ${ }^{\mathrm{TM}}$ Dilution Buffer (STEMCELL Technologies, cat. no. 07183, Canada)

- $\mathrm{TeSR}^{\mathrm{TM}}-\mathrm{E}^{\mathrm{TM}}$ Kit for hESC/hiPSC Maintenance (STEMCELL Technologies, 05940, Canada) contains $\mathrm{TeSR}^{\mathrm{TM}}-\mathrm{E}^{\mathrm{TM}}$ Basal Medium (cat. no. 05991) and
$\mathrm{TeSR}^{\mathrm{TM}}$-E8 ${ }^{\mathrm{TM}}$ 25X Supplement (cat. no. 05992)

- DPBS (PAN BIOTECH, cat. no. P04-36500, Germany)

- Cryostor CS10 (STEMCELL Technologies, cat. no. 07930, Canada)

- TrypLE ${ }^{\mathrm{TM}}$ Select Enzyme (Life Technologies, cat. no. 12605-010, US)

- Gentle Cell Dissociation Reagent (STEMCELL Technologies, cat. no. 07174, Canada)

- STEMdiff ${ }^{\mathrm{TM}}$ Trilineage Differentiation kit (STEMCELL Technologies, 05230, Canada)

- O-cyclic Phytosphingosine-1-phosphate (cP1P, AXCESO BIOPHAMA, Korea)

- $70 \%$ Ethanol (MERCK, cat. no. 1.00974.1011, Germany)

- Isopropanol (MERCK, cat. no. 1.09634.2511, Germany)

\section{Equipment}

- Safety bench, Class II (ILJIN HI-TECH, Korea)

- Refrigerator

- Freezer, $-20 /-80^{\circ} \mathrm{C}$ (Panasonic, MDF-u54v-pk, Japan)

- Micropipettes (GILSON, USA)

- Sterile pipette tips, 100, 200 and 1,000 $\mu 1$ (SARS-

TEDT, Germany)

- $\mathrm{CO}_{2}$ incubator (Thermo Scientific, HERA CELL 240i, USA)

- Water bath, $37^{\circ} \mathrm{C}$ (SAMHEUNG ENERGY, WB$11 \mathrm{GDN}$, Korea)

- Centrifuge (Eppendorf, 5810R, Germany)

- Hood equipped with stereomicroscope (OLYMPUS, SZ61, Japan)

- Light microscope (OLYMPUS, CKX41, Japan)
A

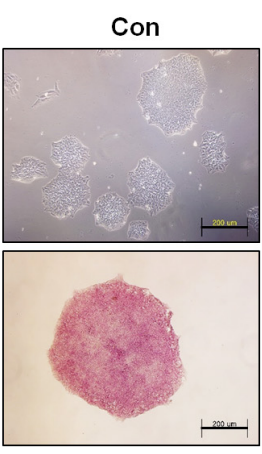

D

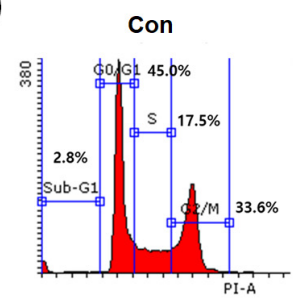

cP1P (100 nM)

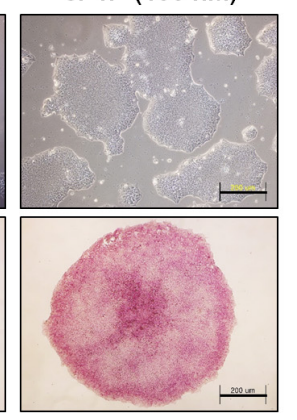

cP1P (100 nM)

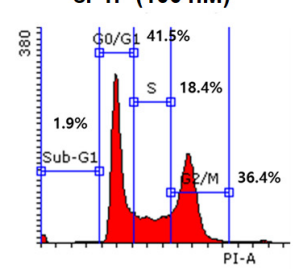

B

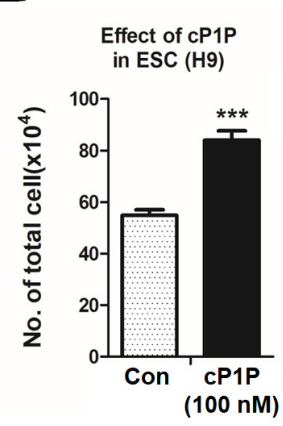

E



C

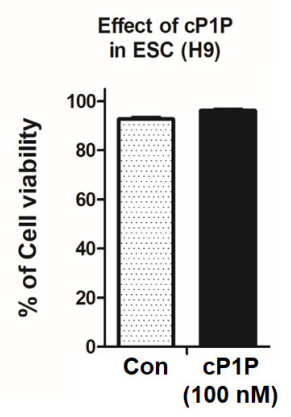

Fig. 3. Supplementation of $\mathrm{CP} 1 \mathrm{P}$ for improving proliferation of hPSCs. CP1P treatment appears to regulate proliferation of hPSCs by the expansion of total cell populations associated with cell cycle progression. (A) Bright-field (top) and AP staining images (bottom) of hPSC plated on vitronectin-coated plate in the absence (Con) and presence of $\mathrm{CP} 1 \mathrm{P}$ (100 mM). All scale bar, $200 \mu \mathrm{m}$. On day 7 , the hPSC cultures were analyzed for total cell count (B), cell viability test (C) and cell cycle (D). (E) Protein expression of pluripotent markers (REX-1, OCT4, and KLF4) between Con and CP1P-treated group were analyzed by western blot. 
- Liquid nitrogen storage tank (CRYO Industries, USA)

- Conical tube, $15 \mathrm{ml}$ (SPL, cat. no. 50015, Korea)

- Conical sterile polypropylene tube, $50 \mathrm{ml}$ (SPL, cat. no. 50050, Korea)

- Sterile serological pipettes, 5, 10 and $50 \mathrm{ml}$ (SPL, cat. no. 91005,91010 and 91050 , Korea)

- $35 \times 10 \mathrm{~mm}$ dish (BD FALCON, cat. no. 353001, USA)

- 6-well plate (CORNING, cat. no. CT-3516, USA)

- Cryogenic handling gloves (Honeywell, USA)

- Forceps (WORLD PRECISION INSTRUMENTS, USA)

- Isopropanol freezing containers (Thermo Scientific, cat. no. 5100-0001, USA)

- Cryovials, $2.0 \mathrm{ml}$ (CORNING, cat. no. CC-430488, USA)

- Cryo $1^{\circ} \mathrm{C}$ freezing container (Nalgene, cat. no. 521000001)

\section{Equipment setup}

Complete TeSRTM-E8TM medium: Thaw $\mathrm{TeSR}^{\mathrm{TM}}-\mathrm{E}^{\mathrm{TM}}$ $25 \times$ supplement at room temperature $\left(15 \sim 25^{\circ} \mathrm{C}\right)$ or overnight $\left(2 \sim 8^{\circ} \mathrm{C}\right)$. Add $20 \mathrm{ml}$ of $\mathrm{TeSR}^{\mathrm{TM}}-\mathrm{E}^{\mathrm{TM}} 20 \times$ supplement to $480 \mathrm{ml}$ of $\mathrm{TeSR}^{\mathrm{TM}}-\mathrm{E} 8^{\mathrm{TM}}$ Basal Medium and mix them thoroughly. Store the complete medium at $2 \sim 8^{\circ} \mathrm{C}$ for up to 2 weeks. If not used immediately, divide the medium into aliquots and store at $-20^{\circ} \mathrm{C}$ for up to 6 months.

- Note: We make $45 \mathrm{ml}$ aliquots of the complete medium in $50 \mathrm{ml}$ sterile polypropylene conical tube. The aliquots may vary depending on the scale of the culture. Once thawed, use within 2 weeks and do not re-freeze. CP1P: Dilute cP1P (MW: 415.92) powder in DMSO or $\mathrm{NaOH}$ to reach $10 \mu \mathrm{M}$ stock solution. Divide the stock solution into aliquots $(25 \sim 100 \mu \mathrm{l} /$ tube $)$ and stored at $20^{\circ} \mathrm{C}$. For use, thaw the stock solution at room temperature and dilute to obtain the desired concentration in complete $\mathrm{TeSR}^{\mathrm{TM}}-\mathrm{E}^{\mathrm{TM}}$ medium. In general, cP1P activity may appear at concentrations of $1 \sim 1000 \mathrm{nM}$ in hPSCs. However, the optimal concentration should be determined according to cell lines or culture conditions.

Vitronectin $\mathrm{XF}^{\mathrm{TM}}$ : Vitronectin XFTM is supplied as a $250 \mu \mathrm{g} / \mathrm{ml}$ concentrated stock solution. Thaw the vial of Vitronectin $\mathrm{XF}^{\mathrm{TM}}$ at room temperature $\left(15 \sim 25^{\circ} \mathrm{C}\right)$ and dilute in CellAdhere ${ }^{\mathrm{TM}}$ dilution buffer or DPBS to reach a final concentration of $10 \mu \mathrm{g} / \mathrm{ml}$ (i.e. dilute $2 \mathrm{ml}$ of Vitronectin $\mathrm{XF}^{\mathrm{TM}}$ stock solution in $48 \mathrm{ml}$ of dilution buffer). If the entire vial will not be used immediately, divide the stock solution into aliquots and store at $-20^{\circ} \mathrm{C}$ or $-80^{\circ} \mathrm{C}$ for long-term storage.
- Note: A $10 \mu \mathrm{g} / \mathrm{ml}$ of working concentration is sufficient to support most of hPSC lines. However, the optimal concentration may vary depending on the cell line. - Note: We make $240 \mu 1$ aliquots of the stock solution in $1.5 \mathrm{ml}$ sterile effendorf tube for coating one 6-well plate $(1 \mathrm{ml} /$ well). The aliquots and coating volume may vary depending on the scale of the culture and cultureware. Once diluted, use immediately within 1 week and do not re-freeze.

ROCK inhibitor: Aseptically add $3.12 \mathrm{ml}$ DPBS (pH 7.2) or sterile water to the $10 \mathrm{mg}$ vial of ROCK inhibitor (MW: 320.26) and mix it thoroughly by pipetting. Aliquot into a vial the stock solution $(10 \mathrm{mM})$ in appropriate working volumes depending on the culture conditions and the scale of the culture. Stock solution is stable at $-20^{\circ} \mathrm{C}$ for up to 6 months.

- Note: If MW of material is not 320.26, dilute appropriately to achieve $10 \mathrm{mM}$ solution. Batch specific MWs may vary from batch to batch due to the degree of hydration, which will affect the solvent volumes required to prepare stock solution.

- Note: Normally we do not recommend the use of ROCK inhibitor. This could be an option for users to enhance cell survival after single cell dissociation for passaging or during initial thawing of cryopreserved hPSCs, as it has been reported. Stock solution should be diluted into culture medium immediately before use.

\section{Procedure}

Matrix and medium preparation (outlining how to coat six wells of non-tissue culture-treated 6-well plate): 1) Thaw an aliquot $(240 \mu \mathrm{l})$ of Vitronectin $\mathrm{XF}^{\mathrm{TM}}$ stock solution at room temperature.

- Note: Avoid additional freeze-thaw cycle.

2) Dilute $240 \mu 1$ of Vitronectin $X^{\mathrm{TM}}$ stock solution in $5.76 \mathrm{ml}$ of CellAdhere ${ }^{\mathrm{TM}}$ Dilution Buffer or DPBS to make $6 \mathrm{ml}$ of a working solution $(10 \mu \mathrm{g} / \mathrm{ml})$ and mix gently (Do not vortex).

3) Add $1 \mathrm{ml}$ of diluted working solution to the center of each well of 6-well plate and gently rock the plate to evenly distribute the solution across the surface.

4) Incubate the plate at room temperature for a minimum $2 \mathrm{~h}$ prior to use.

- Note: If not used immediately, the plates can be prepared for later use. The plates must be sealed tightly with Parafilm ${ }^{\circledR}$ to prevent evaporation and stored at 2 $8^{\circ} \mathrm{C}$ for up to 1 week. Allow stored coated plates to come to room temperature for $30 \mathrm{~min}$ prior to proceeding.

5) While incubation of the coated plates, warm complete $\mathrm{TeSR}^{\mathrm{TM}}-\mathrm{E} 8^{\mathrm{TM}}$ medium at room temperature (15 
$25^{\circ} \mathrm{C}$ ). Do not warm medium in a $37^{\circ} \mathrm{C}$ water bath. - Note: The complete TeSR ${ }^{\mathrm{TM}}-\mathrm{E} 8^{\mathrm{TM}}$ medium is light and temperature sensitive. Do not leave medium at room temperature for longer than $2 \mathrm{~h}$ and avoid exposure to light to prevent degradation of medium components.

6) To prepare the plates for passaging or thawing of hPSCs, remove the excess vitronectin from the plates and wash with CellAdhere ${ }^{\mathrm{TM}}$ dilution buffer or DPBS.

7) Aspirate wash solution and add $2 \mathrm{ml}$ of pre-warmed $\mathrm{TeSR}^{\mathrm{TM}}-\mathrm{E} 8^{\mathrm{TM}}$ medium per well.

8) Place the plates in a $37^{\circ} \mathrm{C}, 5 \% \mathrm{CO}_{2}$ incubator $1 \mathrm{~h}$ before thawing or passaging.

Thawing hPSCs: 1) Take the cryovial out of liquid nitrogen and move them to the tissue culture room on ice.

2) Quickly thaw the cells by gently swirling the vial in a $37^{\circ} \mathrm{C}$ water bath.

3) When only a small particle of ice is left in the vial, wipe the outside of the cryovial with $70 \%(\mathrm{v} / \mathrm{v})$ ethanol to disinfect, dry and bring it under a biosafety cabinet.

4) Gently transfer the aggregates suspension into a 15 $\mathrm{ml}$ conical tube using a 1 or $2 \mathrm{ml}$ serological pipette to minimize breakage of cell aggregates.

5) Add 5 7 $\mathrm{ml}$ of pre-warmed $\mathrm{TeSR}^{\mathrm{TM}}-\mathrm{E}^{\mathrm{TM}}$ medium in a drop-wise manner to the tube.

- Note: While adding drops, gently rock the tube back and forth to minimize osmotic shock to the cells.

6) Centrifuge the mixture at $150 \mathrm{~g}$ for $3 \mathrm{~min}$ at room temperature.

7) Discard the supernatant and re-suspend the aggregates in $1 \mathrm{ml}$ of pre-warmed $\mathrm{TeSR}^{\mathrm{TM}}-\mathrm{E}^{\mathrm{TM}}$ medium.

- Note: While slowly adding warm TeSR ${ }^{\mathrm{TM}}-\mathrm{E} 8^{\mathrm{TM}}$ me-

dium, gently tap the tube to dislodge the cell pellet.

8) Plate the aggregates into one to two wells of vitronectin-coated plate and gently move the plate side to side, back and forth to distribute the aggregates evenly.

- Note: Supplement the medium with a stock solution of ROCK inhibitor to maintain $10 \mu \mathrm{M}$ final concentration (add $1 \mu 1$ of $10 \mathrm{mM}$ ROCK inhibitor for $1 \mathrm{ml}$ of medium) for enhancing cell survival after plating.

9) Incubate the plate at $37^{\circ} \mathrm{C}, 5 \% \mathrm{CO}_{2}$ incubator and do not disturb the plates for $24 \mathrm{~h}$ after plating.

Passaging of hPSCs: The following are the instructions for passaging hPSCs maintained in $\mathrm{TeSR}^{\mathrm{TM}}-\mathrm{E}^{\mathrm{TM}}$ medium in cell aggregates (1. Passaging as cell aggregates) or single cell suspensions (2. Passaging as single cell suspensions). hPSC cultures can be passaged when they are 70 100\% confluent. Before passaging, we recommend removal of spontaneously differentiating area of any colonies using a pipette tip (Fig. 4A).

\section{Passaging as cell aggregates}

Prepare vitronectin-coated plate 1 day before passaging (see Procedure section. Matrix and medium preparation).

1) Remove spent medium from the culture vessel and rinse with DPBS.

2) Add $1 \mathrm{ml}$ of Gentle Cell Dissociation Reagent (GCDR) solution and incubate for 2 6 $\mathrm{min}$ at room temperature $\left(15 \sim 25^{\circ} \mathrm{C}\right)$.

- Note: Observe cells under microscope during incubation to remove the GCDR solution before the colonies are completely detached. The incubation times may vary depending on cell lines.

3) Aspirate the GCDR solution and rinse with $0.5 \mathrm{ml}$ of pre-warmed $\mathrm{TeSR}^{\mathrm{TM}}-\mathrm{E} 8^{\mathrm{TM}}$ medium.

4) Add fresh $1 \mathrm{ml}$ of warm $\mathrm{TeSR}{ }^{\mathrm{TM}}-\mathrm{E} 8^{\mathrm{TM}}$ medium.

5) Gently scrape the colonies with a $5 \mathrm{ml}$ serological pipette or cell scraper and transfer the detached aggregates to a $15 \mathrm{ml}$ conical tube using a $2 \mathrm{ml}$ serological pipette.

6) Triturate the aggregates to create appropriate size (approximately 50 200 $\mu \mathrm{m}$ ) for plating with a $200 \mu 1$ or $1 \mathrm{ml}$ pipette tips.

7) Plate the small aggregates at the desired density onto vitronectin-coated plates containing the complete $\mathrm{TeSR}^{\mathrm{TM}}$ $\mathrm{E} 8{ }^{\mathrm{TM}}$ medium.

- Note: The split ratio should be determined depending on the confluency at the day of passaging and the growth rates of cell lines.

8) Gently move the plate side to side, back and forth to distribute the aggregates evenly.

9) Incubate the plate at $37^{\circ} \mathrm{C}, 5 \% \mathrm{CO}_{2}$ incubator and do not disturb the plates for $24 \mathrm{~h}$ after plating.

10) Feed daily with fresh medium and observe regularly cell growth and morphology (Fig. 4B).

\section{Passaging as single cell suspensions}

1) Remove spent medium from the culture vessel and rinse with DPBS.

2) Add $1 \mathrm{ml}$ of pre-warmed TrypLE to wells and incubate for $5 \mathrm{~min}$ at $37^{\circ} \mathrm{C}, 5 \% \mathrm{CO}_{2}$ incubator.

3) Aspirate the TrypLE solution and rinse with $0.5 \mathrm{ml}$ of pre-warmed $\mathrm{TeSR}^{\mathrm{TM}}-\mathrm{E} 8^{\mathrm{TM}}$ medium.

- Note: The rinsing should be done carefully as the colonies are loosely attached after the TrypLE treatment for $5 \mathrm{~min}$.

4) Add fresh $1 \mathrm{ml}$ of warm $\mathrm{TeSR}{ }^{\mathrm{TM}}-\mathrm{E} 8^{\mathrm{TM}}$ medium and break the colonies to single cell suspensions by gentle trituration with a $1 \mathrm{ml}$ pipette tip.

5) Count the cells using a hemocytometer. Plate the cells at densities of 30,000 50,000 cells per $\mathrm{cm}^{2}$ onto vitronectin-coated plates containing the complete $\mathrm{TeSR}^{\mathrm{TM}}$ - 


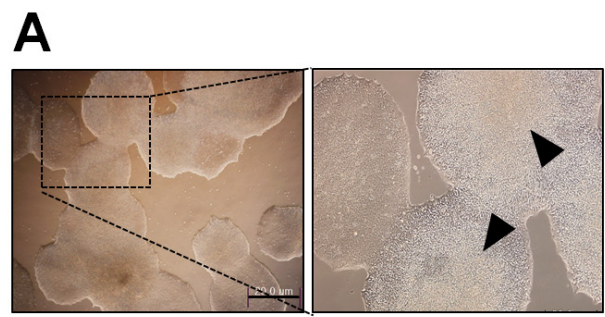

\section{B}


C
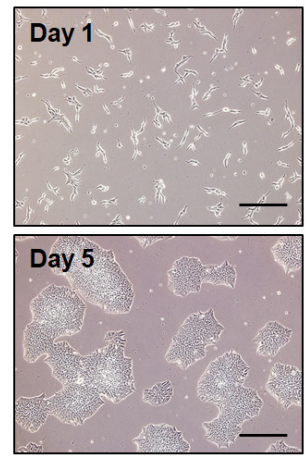

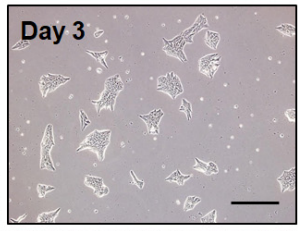

Day 7
Fig. 4. hPSC passaging in cell aggregates and single cell suspensions. (A) Before starting to subculture, highly differentiated colonies or the differentiated section of colonies can be removed by swirling or scratching off with a pipette tip under a dissecting microscope. Black arrows indicate the differentiated section of hPSCs. (B, C) Representative bright field (BF) images of hPSCs passaged in cell aggregates (B) and single cell suspensions (C) during cultures. All scale bar, $200 \mu \mathrm{m}$.
$\mathrm{E} 8^{\mathrm{TM}}$ medium.

- Note: Addition of $10 \mathrm{mM}$ ROCK inhibitor $(1 \mu 1$ of $10 \mathrm{mM}$ ROCK inhibitor per $1 \mathrm{ml}$ of medium) is recommended when plating single cell suspensions for enhancing cell survival.

- Note: Seeding density is critical for the outcome of the passaging. Thus, optimal seeding density should be adjusted empirically for each culture condition (matrix, medium, and culture ware) and each cell line.

6) Gently move the plate side to side, back and forth to distribute the single cell suspensions evenly.

7) Incubate the plate at $37^{\circ} \mathrm{C}, 5 \% \mathrm{CO}_{2}$ incubator and do not disturb the plates for $24 \mathrm{~h}$ after plating.

8) Feed daily with fresh medium and observe regularly cell growth and morphology (Fig. 4C).

Freezing of hPSCs (outlining how to freeze hPSCs that maintained under above culture conditions in cell aggregates): Cultures must be cryopreserved when in their log phase of growth (approximately 70 80\% confluent) to enhance survival upon thawing. We recommend freezing the cell aggregates from one well of one 6-well plate per cryovial. Keep the freezing container and cryoprotectant in a refrigerator 1 day before freezing.

1) Remove spent medium from the culture vessel and rinse with DPBS.

2) Add $1 \mathrm{ml}$ of GCDR and incubate for $6 \sim 12 \mathrm{~min}$ at $37^{\circ} \mathrm{C}, 5 \% \mathrm{CO}_{2}$ incubator.

- Note: Observe cells under microscope during incubation to remove the GCDR before the colonies are completely detached. The incubation times may vary depending on cell lines.

3) Aspirate the GCDR and add fresh warm $\mathrm{TeSR}^{\mathrm{TM}}$ $\mathrm{E} 8^{\mathrm{TM}}$ medium.

4) Gently scrape the colonies with a $5 \mathrm{ml}$ serological pipette or cell scraper.

- Note: Do not use a pipette to avoid breaking the cell aggregates into small pieces or single cells. Leave the aggregates as large as possible.

5) Gently transfer the aggregates suspension into a 15 $\mathrm{ml}$ conical tube using a 1 or $2 \mathrm{ml}$ serological pipette to minimize breakage of cell aggregates.

6) Centrifuge at $150 \mathrm{~g}$ for $3 \mathrm{~min}$ at room temperature.

7) Gently aspirate the supernatant and re-suspend the aggregates in $1 \mathrm{ml}$ of cold CryoStor ${ }^{\circledR}$ CS10.

- Note: While slowly adding cryopropectant, gently tap the tube to dislodge the cell pellet. Care must be taken to minimize the breakup of the aggregates.

8) Transfer the $1 \mathrm{ml}$ suspension of aggregates in a cryovial using a 1 or $2 \mathrm{ml}$ serological pipette.

9) Immediately place the cryovials into a pre-chilled freezing container and keep the aggregates at $-20^{\circ} \mathrm{C}$ for $2 \mathrm{~h}$, followed by $-80^{\circ} \mathrm{C}$ for $2 \mathrm{~h}$.

10) Transfer the aggregates into a liquid nitrogen tank for long-term storage.

- Note: A standard slow rate-controlled cooling protocol can be used for freezing (i.e. Reduce temperature at approximately $-1^{\circ} \mathrm{C} / \mathrm{min}$, followed by long-term storage in liquid nitrogen). 
Routine characterization for long-term maintenance of hPSCs: The longer hPSCs are maintained, the more likely they have some defects in terms of growth, developmental capacity and genomic stability. Defects in developmental capacity refer to changes in the pluripotency of the cells that may occur with time in long-term culture. Thus, it is useful to check periodically hPSC cultures to ensure maintenance of pluripotency during long-term culture using several methodologies. Here, we briefly describe commonly used in vitro approaches to assess the pluripotency of hPSCs.

1. Pluripotency marker expression by immunofluorescence staining (Fig. 5A, 5B)

1) Aspirate the spent medium.

2) Fix the cells with $4 \% \mathrm{PFA}$ in PBS pH 7.4 for $10 \mathrm{~min}$ at room temperature.

3) Incubate the samples for 10 30 min with PBS containing $0.1 \sim 0.4 \%$ Triton X-100. Optimal percentage of Triton X-100 should be determined for each protein of interest.

4) Incubate cells with $1 \% \mathrm{BSA}$ in PBS for $1 \mathrm{~h}$ to block unspecific binding of the antibodies. Alternative blocking solution may use $1 \sim 10 \%$ serum from a goat or donkey; see antibody datasheet for recommendations.

5) Incubate cells in the diluted primary antibody with blocking solution in a humidified chamber for $1 \mathrm{~h}$ at room temperature or overnight at $4^{\circ} \mathrm{C}$.

6) Discard the solution and wash the cells three times in PBS, 5 min each wash.

7) Incubate cells with the secondary antibody in PBS for $1 \mathrm{~h}$ at room temperature in the dark.

8) Repeat step 6.

9) Counter staining with $0.1 \sim 1 \mu \mathrm{g} / \mathrm{ml}$ Hoechst or DAPI for $5 \mathrm{~min}$ in the dark.

10) Rinse with PBS.

11) Analyze samples.

2. Pluripotency marker expression by flow cytometry (Fig. 5C)

1) Harvest, wash the dissociate cells $\left(1 \sim 5 \times 10^{6}\right.$ cells $\left./ \mathrm{ml}\right)$ that were fixed in $100 \mu 1$ of $1 \%$ PFA with $0.1 \sim 0.4 \%$ Triton X-100 or Tween 20 in cold PBS to each sample, then mix gently and incubate for $10 \sim 15 \mathrm{~min}$.

2) Cell down (centrifuge $400 \sim 600 \times \mathrm{g}$ for $5 \mathrm{~min}$ at room temperature) and discard the supernatant.
A
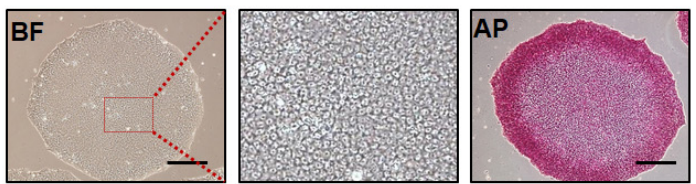

B



DAPI


E-Cadherin
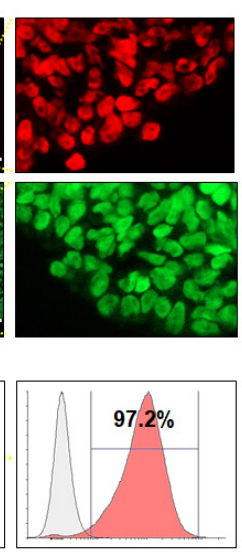

OCT3/4
D
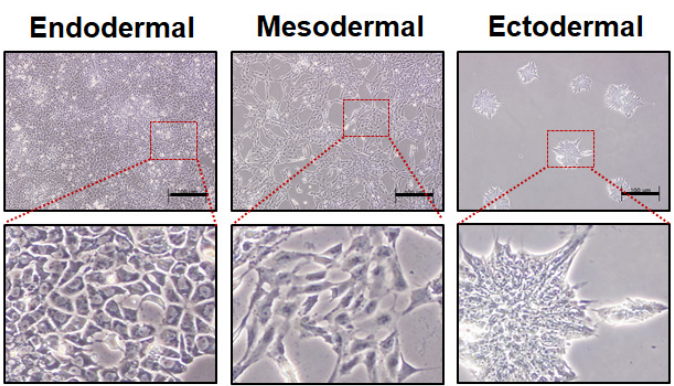

E
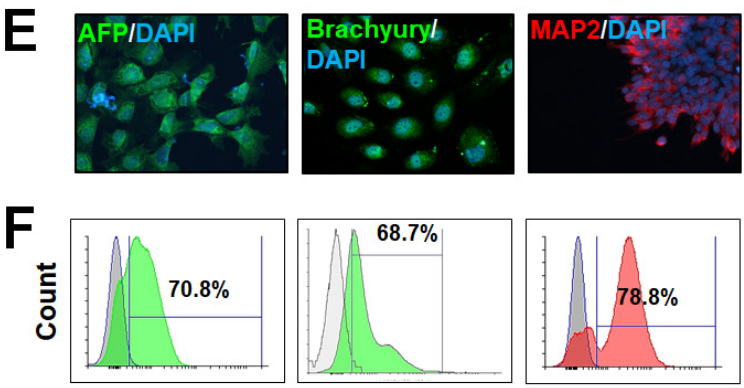

AFP

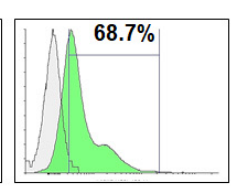

Brachyury

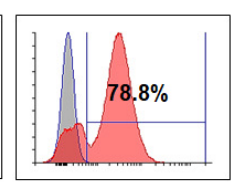

MAP2

Fig. 5. Characterization of hPSCs cultured in chemically defined medium. (A) Representative BF images of hPSCs grown on vitronectin-coated plate in $\mathrm{TeSR}^{\mathrm{TM}}-\mathrm{E}^{\mathrm{TM}}$ medium for 5 days and typical colony morphology of hPSCs with positive AP staining. (B) Immunofluorescence staining of hPSCs for pluropotency markers (OCT3/4, red; SOX2, green). Cell nuclei were counterstained using DAPI (blue). All scale bars, 100 $\mu \mathrm{m}$. (C) Flow cytometry analysis of cultured hPSC for REX-1, E-Cadherin, and OCT3/4. (D) hPSCs were differentiated into three germ-layers using the STEMdiff ${ }^{\mathrm{TM}}$ Trilineage Differentiation Kit. During differentiation, the shape of each differentiated cell types was clearly different (a: Endoderm, b: Mesoderm and c: Ectoderm lineage). On day 7, the cultured and differentiated-hPSCs were analyzed by immunofluorescence staining (E) and flow cytometry (F). All scale bar, $100 \mu \mathrm{m}$. Flow cytometry analysis of differentiated-hPSCs for AFP (endodermal lineage), Brachyury (mesodermal lineage) and MAP2 (ectoderm lineage). 
3) Incubate cells with $1 \%$ BSA in cold PBS for $1 \mathrm{~h}$ to block unspecific binding of antibodies on ice.

4) Repeat step 2.

5) Re-suspend the cell pellet in $100 \mu 1$ of $1 \%$ BSA-PBS with directly conjugated primary antibody and incubate for $30 \sim 60 \mathrm{~min}$ at room temperature. Protect form light.

6) Repeat step 2 .

7) Re-suspend stained cells in an appropriate volume of PBS or FACS buffer.

8) Analyze samples.

\section{In vitro differentiation potential}

The hPSCs have the potential to form derivatives of all three embryonic germ layers. In vitro, the hPSCs were directly differentiated to all three germ layers using the STEMdiff $^{\mathrm{TM}}$ Trilineage Differentiation Kit (see manufacturer's instructions at https://www.stemcell.com/stemdiff-trilineage-differentiation-kit.html), which is commercially available and provides a simple culture assay (ectoderm, mesoderm and endoderm) (Fig. 5D). Immunofluoresencel staining and flow cytomethry analysis showed that ATF (endoderm), Brachyury (mesoderm) and MAP2 (ectoderm) were strongly expressed in differentiated hPSCs (Fig. 5E, 5F).

\section{Anticipated Results}

In this protocol report, we have tested various culture mediums, ECMs and agents for improving hPSCs culture and suggest that xeno-free and chemically defined $\mathrm{TeSR}{ }^{\mathrm{TM}}-\mathrm{E} 8^{\mathrm{TM}}$ in combination with rhVitronectin is suitable for stable maintenance of hPSCs. In addition, the supplementation of bioactive lysophospholipid (cP1P) to the culture conditions improves the proliferation of hPSCs. Xeno-free and chemically defined culture conditions described in this protocol is ideal for reducing lot-to-lot variation and increasing reproducibility, which can ensure consistency for the use of hPSCs in both basic research and clinical applications. Long-term maintenance of hPSCs without compromising safety and functionality in this defined culture system would reduce the economic burden for large-scale expansions for various applications.

\section{Acknowledgments}

This research was supported by a grant from the Korea Centers for Disease Control and Prevention (2017ER610300) and the Bio and Medical Technology Development Program (2017M3A9B3061830) of the National Research Foundation (NRF). We are also grateful to Axceso Biopharma Co., Ltd. for providing cP1P and for excellent technical assistance.

\section{Potential Conflict of Interest}

The authors have no conflicting financial interest.

\section{References}

1. Thomson JA, Itskovitz-Eldor J, Shapiro SS, Waknitz MA, Swiergiel JJ, Marshall VS, Jones JM. Embryonic stem cell lines derived from human blastocysts. Science 1998;282: $1145-1147$

2. Yu J, Vodyanik MA, Smuga-Otto K, Antosiewicz-Bourget J, Frane JL, Tian S, Nie J, Jonsdottir GA, Ruotti V, Stewart $\mathrm{R}$, Slukvin II, Thomson JA. Induced pluripotent stem cell lines derived from human somatic cells. Science 2007;318: 1917-1920

3. Dakhore S, Nayer B, Hasegawa K. Human pluripotent stem cell culture: current status, challenges, and advancement. Stem Cells Int 2018;2018:7396905

4. Xu C, Inokuma MS, Denham J, Golds K, Kundu P, Gold JD, Carpenter MK. Feeder-free growth of undifferentiated human embryonic stem cells. Nat Biotechnol 2001;19:971974

5. Richards M, Fong CY, Chan WK, Wong PC, Bongso A. Human feeders support prolonged undifferentiated growth of human inner cell masses and embryonic stem cells. Nat Biotechnol 2002;20:933-936

6. Richards M, Tan S, Fong CY, Biswas A, Chan WK, Bongso A. Comparative evaluation of various human feeders for prolonged undifferentiated growth of human embryonic stem cells. Stem Cells 2003;21:546-556

7. Ludwig TE, Levenstein ME, Jones JM, Berggren WT, Mitchen ER, Frane JL, Crandall LJ, Daigh CA, Conard KR, Piekarczyk MS, Llanas RA, Thomson JA. Derivation of human embryonic stem cells in defined conditions. Nat Biotechnol 2006;24:185-187

8. Chen G, Gulbranson DR, Hou Z, Bolin JM, Ruotti V, Probasco MD, Smuga-Otto K, Howden SE, Diol NR, Propson NE, Wagner R, Lee GO, Antosiewicz-Bourget J, Teng JM, Thomson JA. Chemically defined conditions for human iPSC derivation and culture. Nat Methods 2011;8:424-429

9. Yasuda SY, Ikeda T, Shahsavarani H, Yoshida N, Nayer B, Hino M, Sharma NV, Suemori H, Hasegawa K. Chemically defined and growth-factor-free culture system for the expansion and derivation of human pluripotent stem cells Nat Biomed Eng 2018;2:173-182

10. Phadnis SM, Loewke NO, Dimov IK, Pai S, Amwake CE, Solgaard O, Baer TM, Chen B, Pera RAR. Dynamic and social behaviors of human pluripotent stem cells. Sci Rep 2015;5:14209

11. Jacobs K, Zambelli F, Mertzanidou A, Smolders I, Geens M, Nguyen HT, Barbé L, Sermon K, Spits C. Higher-density culture in human embryonic stem cells results in DNA damage and genome instability. Stem Cell Reports 2016;6: 330-341

12. Hongisto H, Vuoristo S, Mikhailova A, Suuronen R, Virtanen I, Otonkoski T, Skottman H. Laminin-511 ex- 
pression is associated with the functionality of feeder cells in human embryonic stem cell culture. Stem Cell Res 2012;8:97-108

13. Inzunza J, Gertow $\mathrm{K}$, Strömberg MA, Matilainen E, Blennow E, Skottman H, Wolbank S, Ahrlund-Richter L, Hovatta O. Derivation of human embryonic stem cell lines in serum replacement medium using postnatal human fibroblasts as feeder cells. Stem Cells 2005;23:544-549

14. Viswanathan P, Gaskell T, Moens N, Culley OJ, Hansen D, Gervasio MK, Yeap YJ, Danovi D. Human pluripotent stem cells on artificial microenvironments: a high content perspective. Front Pharmacol 2014;5:150

15. Clause KC, Barker TH. Extracellular matrix signaling in morphogenesis and repair. Curr Opin Biotechnol 2013;24: 830-833

16. Kefalides NA. Structure and biosynthesis of basement membranes. Int Rev Connect Tissue Res 1973;6:63-104

17. Timpl R, Rohde H, Risteli L, Ott U, Robey PG, Martin GR. Laminin. Methods Enzymol 1982;82 Pt A:831-838

18. Timpl R, Rohde H, Robey PG, Rennard SI, Foidart JM, Martin GR. Laminin--a glycoprotein from basement membranes. J Biol Chem 1979;254:9933-9937

19. Chung AE, Jaffe R, Freeman IL, Vergnes JP, Braginski JE, Carlin B. Properties of a basement membrane-related glycoprotein synthesized in culture by a mouse embryonal carcinoma-derived cell line. Cell 1979;16:277-287

20. Hassell JR, Robey PG, Barrach HJ, Wilczek J, Rennard SI, Martin GR. Isolation of a heparan sulfate-containing proteoglycan from basement membrane. Proc Natl Acad Sci U S A 1980;77:4494-4498

21. Carlin B, Jaffe R, Bender B, Chung AE. Entactin, a novel basal lamina-associated sulfated glycoprotein. J Biol Chem 1981;256:5209-5214

22. Cooper AR, MacQueen HA. Subunits of laminin are differentially synthesized in mouse eggs and early embryos. Dev Biol 1983;96:467-471

23. Ekblom P, Vestweber D, Kemler R. Cell-matrix interactions and cell adhesion development. Annu Rev Cell Biol 1986;2:27-47

24. Hierck BP, Thorsteinsdóttir S, Niessen CM, Freund E, Iperen LV, Feyen A, Hogervorst F, Poelmann RE, Mummery CL, Sonnenberg A. Variants of the alpha 6 beta 1 laminin receptor in early murine development: distribution, molecular cloning and chromosomal localization of the mouse integrin alpha 6 subunit. Cell Adhes Commun 1993;1:33-53

25. Cooper HM, Tamura RN, Quaranta V. The major laminin receptor of mouse embryonic stem cells is a novel isoform of the alpha 6 beta 1 integrin. J Cell Biol 1991;115:843-850

26. Kleinman HK, McGarvey ML, Liotta LA, Robey PG, Tryggvason $\mathrm{K}$, Martin GR. Isolation and characterization of type IV procollagen, laminin, and heparan sulfate proteoglycan from the EHS sarcoma. Biochemistry 1982;21: 6188-6193

27. Kleinman HK, McGarvey ML, Hassell JR, Martin GR. Formation of a supramolecular complex is involved in the reconstitution of basement membrane components. Biochemistry 1983;22:4969-4974

28. Mackay AR, Gomez DE, Cottam DW, Rees RC, Nason AM, Thorgeirsson UP. Identification of the $72-\mathrm{kDa}$ (MMP-2) and 92-kDa (MMP-9) gelatinase/type IV collagenase in preparations of laminin and Matrigel. Biotechniques 1993; 15:1048-1051

29. Vukicevic S, Kleinman HK, Luyten FP, Roberts AB, Roche NS, Reddi AH. Identification of multiple active growth factors in basement membrane Matrigel suggests caution in interpretation of cellular activity related to extracellular matrix components. Exp Cell Res 1992;202:1-8

30. Borg TK. It's the matrix! ECM, proteases, and cancer. Am J Pathol 2004;164:1141-1142

31. Li J, Bardy J, Yap LY, Chen A, Nurcombe V, Cool SM, Oh SK, Birch WR. Impact of vitronectin concentration and surface properties on the stable propagation of human embryonic stem cells. Biointerphases 2010;5:FA132-FA142

32. Doolittle JM, Gomez SM. Structural similarity-based predictions of protein interactions between HIV-1 and Homo sapiens. Virol J 2010;7:82

33. Juliano RL, Varner JA. Adhesion molecules in cancer: the role of integrins. Curr Opin Cell Biol 1993;5:812-818

34. Braam SR, Zeinstra L, Litjens S, Ward-van Oostwaard D, van den Brink $S$, van Laake $L$, Lebrin F, Kats $P$, Hochstenbach R, Passier R, Sonnenberg A, Mummery CL. Recombinant vitronectin is a functionally defined substrate that supports human embryonic stem cell self-renewal via alphavbeta5 integrin. Stem Cells 2008;26:2257-2265

35. Pulido D, Hussain SA, Hohenester E. Crystal structure of the heterotrimeric integrin-binding region of laminin-111. Structure 2017;25:530-535

36. Chen KG, Mallon BS, McKay RD, Robey PG. Human pluripotent stem cell culture: considerations for maintenance, expansion, and therapeutics. Cell Stem Cell 2014;14:13-26

37. Li Y, Powell S, Brunette E, Lebkowski J, Mandalam R. Expansion of human embryonic stem cells in defined serum-free medium devoid of animal-derived products. Biotechnol Bioeng 2005;91:688-698

38. Domogatskaya A, Rodin S, Boutaud A, Tryggvason K. Laminin-511 but not -332, -111, or -411 enables mouse embryonic stem cell self-renewal in vitro. Stem Cells 2008;26: 2800-2809

39. Rodin S, Domogatskaya A, Ström S, Hansson EM, Chien $\mathrm{KR}$, Inzunza J, Hovatta O, Tryggvason K. Long-term self-renewal of human pluripotent stem cells on human recombinant laminin-511. Nat Biotechnol 2010;28:611-615

40. Rodin S, Antonsson L, Hovatta O, Tryggvason K. Monolayer culturing and cloning of human pluripotent stem cells on laminin-521-based matrices under xeno-free and chemically defined conditions. Nat Protoc 2014;9:23542368

41. Villa-Diaz LG, Kim JK, Laperle A, Palecek SP, Krebsbach $\mathrm{PH}$. Inhibition of focal adhesion kinase signaling by integrin $\alpha 6 \beta 1$ supports human pluripotent stem cell selfrenewal. Stem Cells 2016;34:1753-1764 
42. Pyne S, Pyne NJ. Sphingosine 1-phosphate signalling and termination at lipid phosphate receptors. Biochim Biophys Acta 2002;1582:121-131

43. Spiegel S, Milstien S. Sphingosine 1-phosphate, a key cell signaling molecule. J Biol Chem 2002;277:25851-28584

44. Draper JS, Fox V. Human embryonic stem cells: multilineage differentiation and mechanisms of self-renewal. Arch Med Res 2003;34:558-564

45. Inniss $\mathrm{K}$, Moore $\mathrm{H}$. Mediation of apoptosis and pro- liferation of human embryonic stem cells by sphingosine-1-phosphate. Stem Cells Dev 2006;15:789-796

46. Kim MK, Park KS, Lee H, Kim YD, Yun J, Bae YS. Phytosphingosine-1-phosphate stimulates chemotactic migration of L2071 mouse fibroblasts via pertussis toxin-sensitive G-proteins. Exp Mol Med 2007;39:185-194

47. Pata MO, Hannun YA, Ng CK. Plant sphingolipids: decoding the enigma of the Sphinx. New Phytol 2010;185:611-630 